\title{
Zespół Riccietum fluitantis Slavnić 1956 w starorzeczach południowo-zachodniej Polski
}

\author{
$\dagger$ Krzysztof SpaŁeK i Adam Stebel
}

\begin{abstract}
†SpaŁeK, K. And Stebel, A. 2020. Riccietum fluitantis Slavnić 1956 in oxbow lakes of southwestern Poland. Fragmenta Floristica et Geobotanica Polonica 27(2): 269-276. Kraków. e-ISSN 2449-8890, ISSN 1640-629X.

AвstRACT: The paper presents the distribution and habitat conditions of Riccietum fluitantis Slavnić 1956 (Lemnetea minoris class) in oxbow lakes of south-western Poland. During research done in 2000-2018, 11 localities of this community were found. The main threats to Riccietum fluitantis in oxbow lakes in south-western Poland are changes in water levels and physicochemical properties. Problems associated with distinguishing Riccietum fluitantis are discussed.
\end{abstract}

KEY WORDS: distribution, liverworts, Odra river basin, phytosociology, plant communities

K. Spałek, Zakład Botaniki, Instytut Biologii, Uniwersytet Opolski, ul. Oleska 22, 45-052 Opole, Polska

A. Stebel, Katedra i Zakład Botaniki Farmaceutycznej i Zielarstwa, Wydziat Nauk Farmaceutycznych, Ślqski Uniwersytet Medyczny w Katowicach, ul. Ostrogórska 30, 41-200 Sosnowiec, Polska; e-mail:astebel@sum.edu.pl

\begin{abstract}
WSTĘP
Fitocenozy Riccietum fluitantis Slavnić 1956 zostały po raz pierwszy opisane z Vojvodiny w obecnej Serbii (SLAVNIĆ 1956). Riccietum fluitantis występuje rzadko w płytkich, stojących, oligotroficznych, eutroficznych i mezotroficznych wodach Europy (MÜLLER \& GöRS 1960; Hilbig 1971; HejnÝ \& HusÁk 1978; РotT 1980, 1995, SChratT 1993; OT’AHEL'ová 1995; Schubert i in. 1995; Passarge 1996; Matuszkiewicz 2005; Šumberová 2011). Dotychczas wyróżniono trzy jego podzespoły: Riccietum fluitantis typicum, Riccietum fluitantis lemnetosum trisulcae (MÜLLER \& GöRs 1960; POTT 1980) oraz Riccietum fluitantis riciocarpetosum natantis (PASSARGE 1996).

W Polsce zespół ten znany jest z rozproszonych stanowisk w całym kraju (np. PoDBIELKOWSKI 1968; HEREŹNIAK 1972; KRZYWAŃSKI 1974, 1978; TOMASZEWICZ 1979; OCHYRA 1985; WiLCZYŃSKa 1988; KuCHARCZYK 1996; MACICKA-PAWLIK \& WilCZYŃSKA 1996; KącKi i in. 1998; Stebel \& Stebel 1998; Spalek 2005; ProćKów \& SzCZę́́niaK 2009). W większości prac podawany był w szerokim ujęciu, tj. włączano tu płaty, w których miał znaczny udział lub dominował inny gatunek pleustonowego wątrobowca - Ricciocarpos
\end{abstract}


natans. Część autorów przyjmuje wąskie ujęcie zespołu Riccietum fluitantis (np. MATUSZKIEWICZ 2005), włączając tu tylko płaty z dominacją Riccia fluitans, natomiast płaty z przewagą Ricciocarpos natans traktowane są jako odrębny zespół Ricciocarpetum natantis Segal 1963 em. R. Tx. 1974. Taki pogląd przyjęty został w niniejszej pracy. Riccietum fluitantis rozwija się zazwyczaj w szybko nagrzewanych, osłoniętych od wiatru, małych zbiornikach, m.in. starorzeczach, dołach potorfowych, stawach hodowlanych i lejkach krasowych.

Celem pracy było przedstawienie aktualnego rozmieszczenia i charakterystyki fitosocjologicznej Riccietum fluitantis w starorzeczach południowo-zachodniej Polski.

\section{MATERIAE I METODY}

Badania geobotaniczne na terenie starorzeczy w południowo-zachodniej Polsce na Dolnym Śląsku i Śląsku Opolskim przeprowadzono w latach 2000-2018. Badaniami objęto starorzecza Odry i jej większych dopływów: Baryczy, Bobru, Małej Panwi, Nysy Kłodzkiej, Oławy i Stobrawy. Riccietum fluitantis scharakteryzowano na podstawie zdjęć fitosocjologicznych wykonanych metodą Braun-Blaqueta (BRAUN-BLANQUET 1964; DZWONKo 2007). Do zdjęć fitosocjologicznych wybierano płaty jednorodne i reprezentatywne dla fitocenoz o większych powierzchniach. W przypadku fitocenoz o niewielkich powierzchniach zdjęcia obejmowały cały płat.

W celu scharakteryzowania jego warunków siedliskowych, prócz składu gatunkowego, notowano również rodzaj podłoża, głębokość i pH wody. Głębokość mierzono za pomocą wycechowanego sznura obciążonego kotwiczką. Odczyn wody mierzono za pomocą pH-metrów Elmetron CP-315 oraz Conbest CP-102.

Systematykę zbiorowisk roślinnych i nazewnictwo zespołów przyjęto za RENNWALDEM (2000) i MATUSZKIEWICZEM (2005). Nomenklaturę gatunków roślin naczyniowych przyjęto według MIRKA i in. (2002).

\section{WYNIKI}

W trakcie badań prowadzonych w latach 2000-2018 przez pierwszego z autorów na terenie starorzeczy w południowo-zachodniej Polsce zostało stwierdzonych 11 stanowisk Riccietum fluitantis. Większość z nich to starorzecza Odry, tylko w jednym przypadku było to starorzecze Małej Panwi koło Zawadzkiego.

Wykaz stanowisk: Bełcz Wielki (współrzędne geograficzne 51³6'49,912"N, $\left.16^{\circ} 22^{\prime} 8,461^{\prime \prime} \mathrm{E}\right)$, Buszkowice $\left(51^{\circ} 28^{\prime} 19,029^{\prime \prime} \mathrm{N}, 16^{\circ} 26^{\prime} 20,085^{\prime \prime} \mathrm{E}\right)$, Głobice $\left(51^{\circ} 38^{\prime} 12,605^{\prime \prime} \mathrm{N}\right.$, $\left.16^{\circ} 20^{\prime} 42,667^{\prime \prime} \mathrm{E}\right)$, Głogów (51 $\left.40^{\prime} 41,436^{\prime \prime} \mathrm{N}, 16^{\circ} 5^{\prime} 36,135^{\prime \prime} \mathrm{E}\right)$, Nowe Kolnie (5051'37,03"N, $\left.17^{\circ} 34^{\prime} 53,11^{\prime \prime} \mathrm{E}\right)$, Prawików $\left(51^{\circ} 14^{\prime} 10,657^{\prime \prime} \mathrm{N}, 16^{\circ} 30^{\prime} 23,383^{\prime \prime} \mathrm{E}\right)$, Prężyce $\left(51^{\circ} 14^{\prime} 2,338^{\prime \prime} \mathrm{N}\right.$, $\left.16^{\circ} 50^{\prime} 18,109^{\prime \prime} \mathrm{E}\right)$, Przyborów (51 $\left.26^{\prime} 15,518^{\prime \prime} \mathrm{N}, 16^{\circ} 27^{\prime} 9,650^{\prime \prime} \mathrm{E}\right)$, Stary Górnik (5057'21,648'N, $\left.17^{\circ} 20^{\prime} 21,751^{\prime \prime} \mathrm{E}\right)$, Tarchalice $\left(51^{\circ} 21^{\prime} 54,597^{\prime \prime} \mathrm{N}, 1^{\circ} 29^{\prime} 13,074^{\prime \prime} \mathrm{E}\right)$, Zawadzkie $\left(50^{\circ} 36^{\prime} 15,988^{\prime \prime} \mathrm{N}\right.$, $\left.18^{\circ} 30^{\prime} 24,086^{\prime \prime} \mathrm{E}\right)$.

Zespół Riccietum fluitantis rozwija się w miejscach nasłonecznionych i szybko nagrzewających się, osłoniętych od wiatru, w wodach mezotroficznych i eutroficznych, o głębokości 5-80 cm i pH 6,9-8,2 na podłożu mulistym, mulisto-piaszczystym lub piaszczystym. Zazwyczaj zajmuje niewielkie powierzchnie, sięgające maksymalnie $5-50 \mathrm{~m}^{2}$. Jedynie w starorzeczu Odry w Głogowie występuje na powierzchni około 1 ha. Fitocenozy Riccietum fluitantis zlokalizowane są najczęściej w części przybrzeżnej, gdzie często tworzą kompleks mozaikowy ze zbiorowiskami szuwarowymi. 
Zdjęcia fitosocjologiczne zestawiono w tabeli 1 . W większości płatów zbiorowisko to ma budowę dwuwarstwową, rzadziej jednowarstwową. W warstwie podwodnej dominuje Riccia fluitans z mniejszym udziałem Lemna trisulca i Ceratophyllum demersum, natomiast warstwę nawodną tworzy Lemna minor. W płatach zaznacza się niewielki udział Spirodela polyrhiza. Notowano w nich od 3 do 5, średnio 4 gatunków. Łącznie w jego fitocenozach zanotowano 13 gatunków roślin.

\section{DYSKUSJA}

Płaty zespołu Riccietum fluitantis stwierdzone w starorzeczach południowo-zachodniej Polski, ze względu na skład florystyczny, należy zaliczyć do podzespołu Riccietum fluitantis typicum (MÜLlER \& GöRS 1960; POTT 1980). Większość ze starorzeczy, w których je stwierdzono, jest silnie zeutrofizowana, co widoczne jest zwłaszcza w zbiornikach położonych wśród pól i łąk. Eutrofizacja stanowi zagrożenie zarówno dla istnienia stanowisk tego zespołu, jak również samego starorzecza. Te same czynniki powodują zanik fitocenoz Riccietum fluitantis np. w Niemczech, Czechach i na Słowacji (OT'AHEL'ová 1995; ReNNWALD 2000; ŠUMBEROVÁ 2011). Płaty omawianego zespołu w starorzeczach południowozachodniej Polski należą do jednych z najrzadziej spotykanych i zagrożonych wymarciem zbiorowisk z klasy Lemnetea minoris. Ich istnienie zależy przede wszystkim od poziomu wody w starorzeczach oraz stopnia jej eutrofizacji, czyli drastycznych zmian w właściwościach fizyko-chemicznych ich wód.

Nie bez znaczenia jest fakt, że regulowanie koryta rzeki Odry od XVIII w. oraz budowa wałów przeciwpowodziowych zatrzymało generalnie powstawanie nowych starorzeczy. Istniejące podlegają procesowi lądowacenia i w konsekwencji zanikają. Żyzne tereny dolin rzecznych są obecnie w większości intensywnie użytkowane rolniczo. Zarówno odcięcie, jak i zmiana użytkowania z pewnością miały i mają wpływ na tempo znikania starorzeczy, a tym samym na zespoły roślin i zwierząt je zasiedlające (ORZECHOwSKI 2012). Niewątpliwie bardzo negatywny wpływ na rozwój roślinności w starorzeczach mają notowane z roku na rok coraz większe susze.

Wyróżnianie odrębnych zespołów Ricciocarpetum natantis i Riccietum fluitantis ze względu na ich podobieństwo w składzie florystycznym i zajmowanie podobnych siedlisk może budzić wątpliwości. W przypadku Riccietum fluitantis dodatkowym problemem jest gatunek charakterystyczny i dominujący tego zespołu, co nie było nigdy przedmiotem dyskusji w literaturze fitosocjologicznej.

Riccia fluitans L. (wgłębka wodna) znana była botanikom już wcześniej (VAILlANT 1723; Dillenius 1741), zanim pod obecnie akceptowaną nazwą podał ją LinNeusz (1753). Wraz z pokrewnymi gatunkami zaliczana jest do sekcji Ricciella (A. Braun.) Bisch., która obejmuje 19 gatunków rosnących w różnych rejonach świata (SÖDERSTRÖM i in. 2015). Z obecnego terenu Polski po raz pierwszy podał ją MattuschKa (1779) z Dolnego Śląska.

Oprócz niej z sekcji Ricciella występuja jeszcze w Polsce 4 gatunki - opisana w XVIII w. R. canaliculata Hoffm. (Hoffmann 1796), następnie R. huebeneriana Lindenb. (LindenBERG 1837) oraz R. duplex Lorb. ex Müll.Frib i R. rhenana Lorb. ex Müll.Frib. (LORBEER 1934; 


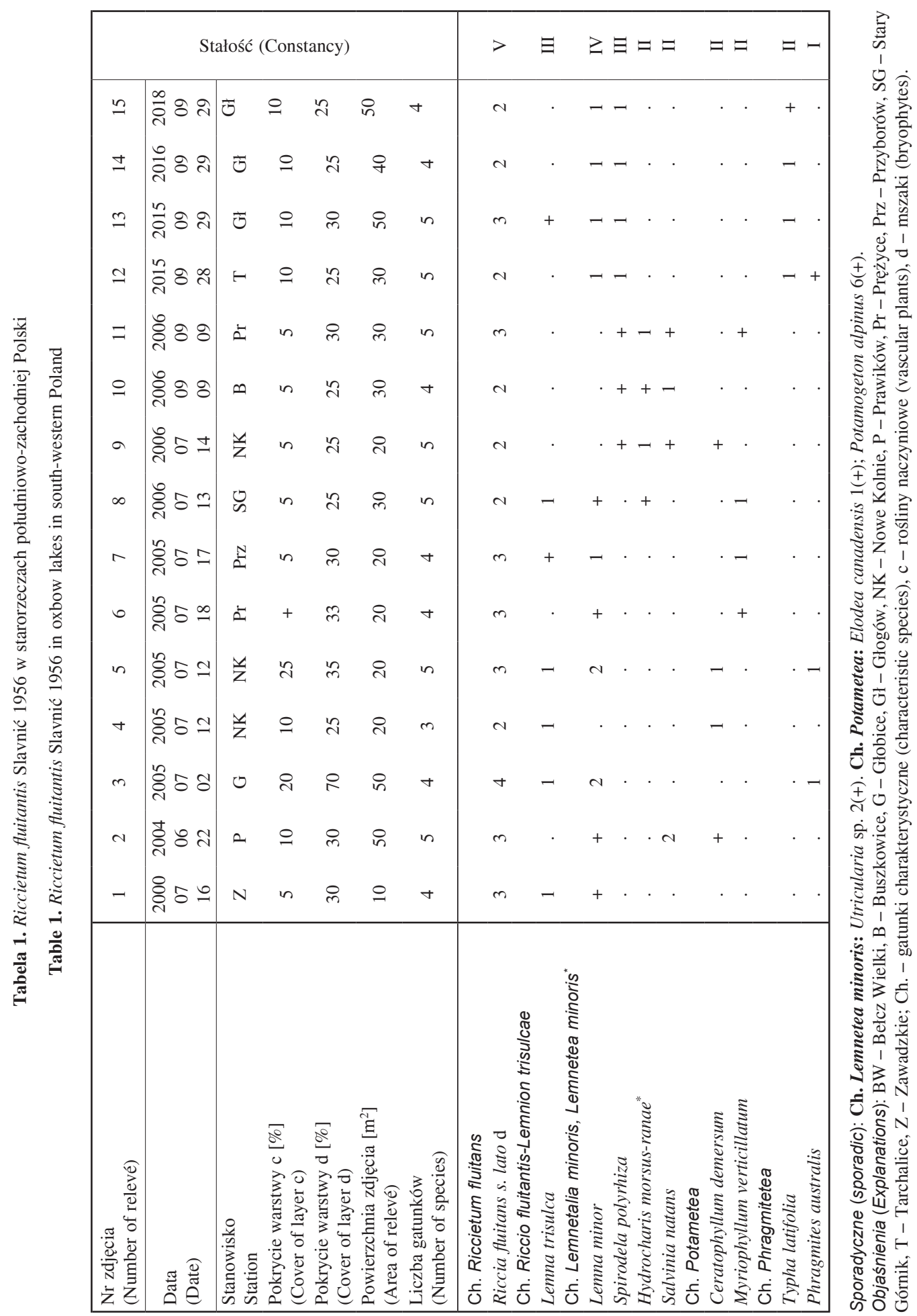


MüLLER 1941). Ich występowanie na terenie kraju jest słabo poznane ze względu na duże podobieństwo form wodnych, w jakich są najczęściej obserwowane. Poprawne oznaczenia tych gatunków są możliwe praktycznie tylko w przypadku obecności form lądowych. Dodatkowo, w Europie pojawił się pochodzący z obszarów tropikalnych kolejny gatunek, Riccia stenophylla, morfologicznie bardzo podobny do R. fluitans (DAMSOLT 2002). Relatywnie często spotykana jest $R$. rhenana, najbardziej spokrewniona z $R$. fluitans. Przykładowo, przeprowadzona ostatnio rewizja materiałów zielnikowych (81 okazów) gatunków z sekcji Ricciella z terenu województwa śląskiego wykazała, że oznaczalne formy lądowe stanowią odpowiednio: 25,8\% Riccia fluitans s. stricto, 19,8\% R. rhenana i 3,7\% R. canaliculata (Stebel 2019). Reszta, 40,7\%, należy do Riccia fluitans s. lato (formy wodne). Odróżnienie Riccia fluitans od R. rhenana stanowi więc największy problem.

Badania na temat morfologii form wodnych i lądowych tych gatunków prowadzili m.in. Müller (1941), Klingmüller (1958) oraz Rivola (1967), podając cechy pozwalające odróżnić także formy wodne. Najważniejszą z nich, która może być pomocna w terenie, jest kąt rozgałęzienia plech, który u Riccia fluitans ma być bardziej ostry, do $75^{\circ}$, w przeciwieństwie do $R$. rhenana, u której ma wynosić 80-105. Formy lądowe różnią się wyraźniej, ponieważ u $R$. fluitans pokrój plechy nie ulega zmianie, natomiast u $R$. rhenana staje się ona krótsza, szersza, na szczytach rozszerzona. Cechy te nie są jednak stałe i niektórzy autorzy (np. SchumACKER \& VÁŇA 2005) uważają, że nie należy traktować tych wątrobowców jako odrębne gatunki. W Polsce Riccia rhenana znana jest z różnych regionów (SobotKa 1958; SzWeykowski \& Koźlicka 1966; KoŁa \& TurzańsKa 1995; STEBEL \& KRAJEWSKi 2019).

W pracach fitosocjologicznych dotyczących zbiorowisk pleustonowych prawie wszystkie notowania podawane są jako Riccia fluitans, a w pracach briologicznych formy wodne także są najczęściej traktowane jako ten gatunek, co może sztucznie zawyżać częstość jego występowania. Jest rzeczą interesującą, że problem występowania $R$. rhenana w fitocenozach Riccietum fluitantis poruszał już PoDBIELKOwSKI (1968), pisząc „Podanego przez Miyawaki i Tüxena (...) drugiego gatunku Riccia - Riccia rhenana - nie odnalazłem w badanym przeze mnie Riccietum fluitantis, natomiast znajdowałem go w postaci formy lądowej pośród roślinności pionierskiej na dnie osuszonych stawów". W celu odróżnienia omawianych wątrobowców w terenie należy sprawdzić, czy np. w miejscu wykonywania zdjęcia fitosocjologicznego nie występują formy lądowe, osiadłe na wysychających brzegach. Można też zebrać nieco plech i w pracowni hodować je na wilgotnej glebie. Takie rozwiązanie proponują np. SzWEYKowski i KoźLICKA (1966) oraz DAMSHOLT (2002). Jeżeli oznaczenie nie jest możliwe, taka informacja powinna być zawarta w pracy, czy też zdjęciu fitosocjologicznym (np. przez zapis Riccia fluitans s. lato).

Interesującym problemem badawczym jest poszukiwanie odpowiedzi na pytania - czy gatunki z sekcji Ricciella budujące fitocenozy pleustonowe różnią się warunkami występowania oraz jaki jest ich udział w budowie poszczególnych płatów.

Podziękowania. Praca finansowana była w ramach badań statutowych Katedry i Zakładu Botaniki Farmaceutycznej i Zielarstwa ŚUM: KNW-1-057/K/9/0. 


\section{LITERATURA}

Braun-Blanquet J. 1964. Pflanzensoziologie, Grundzüge der Vegetationskunde. Dritte Auflage. s. 865. Springer Verlag, Wien - New York.

DAMSholt K. 2002. Illustrated Flora of Nordic Liverworts and Hornworts. s. 840. Lund, Nordic Bryological Society.

Dillenius J. J. 1741. Historia muscorum in qua circiter sexcentae species veteres et novae ad sua genera relatae describuntur et iconibus genuinis illustrantur cum appendice et indice synonymorum. e Theatro Sheldoniano, Oxonii.

Dzwonko Z. 2007. Przewodnik do badań fitosocjologicznych. s. 308. Sorus, Instytut Botaniki Uniwersytetu Jagiellońskiego, Poznań - Kraków.

HejnÝ S. \& HusÁK Š. 1978. Higher plant communities. - W: D. DYKYJovÁ \& J. KVĚT (red.), Pond littoral ecosystems. s. 23-64, 93-95. Springer Verlag, Berlin - Heidelberg - New York.

HereźniaK J. 1972. Zbiorowiska roślinne doliny Widawki. - Monographiae Botanicae 35: 3-160.

HILBIG W. 1971. Übersicht über die Pflanzengesellschaften des südlichen Teiles der DDR. 1. Die Wasserpflanzengesellschaften. - Hercynia 8(1): 4-33.

HofFmanN G. F. 1796. Deutschlands Flora oder botanisches Taschenbuch. Zweyter Theil für das Jahr 1795. Cryptogamie. Béy Johann Jacob Palm. Erlangen.

KącKi Z., AnioŁ-Kwiatkowska J. \& Dajdok Z. 1998. Roślinność dolin wybranych strumieni zlewni Oziąbela. I. Zbiorowiska wodne, bagienne i łąkowe. - Acta Universitatis Wratislaviensis 2036, Prace Botaniczne 74: 109-164.

KLINGMÜLleR W. 1958 Zur Systematik der Ricciaceen des fluitans-Formenkreises: Riccia media n.sp. - Flora oder Allgemaine Botanische Zeitung 146(4): 616-624.

Koła W. \& TurZAŃsKa M. 1995. Wątrobowce (Hepaticopsida) i glewiki (Anthocerophytina). Klucz do oznaczania. Część I. Wątrobowce plechowate i glewiki. s. 152. Wydawnictwo Uniwersytetu Wrocławskiego, Wrocław.

KRZYWAŃSKI J. 1974. Zbiorowiska roślinne starorzeczy środkowej Warty. - Monographiae Botanicae 43: $1-80$.

KRZYWAŃSKI J. 1978. Zbiorowiska roślinne starorzeczy Pilicy między Sulejowem a Tomaszowem Mazowieckim. - Acta Universitatis Lodziensis Folia Botanica 20: 107-137.

KUCHARCZYK M. 1996. Zespoły i zbiorowiska roślinne Kazimierskiego Parku Krajobrazowego II. Zespoły wodne i szuwarowe. - Annales Universitatis Mariae Curie-Skłodowska Sectio C 51: 133-183.

Lindenberg J. B. W. 1837. Monographiae der Riccien. - Nova Acta Academ. Leopoldina 18: 361-504 ('1936').

LinNAEUS C. 1753. Species plantarum, exhibentes plantas rite cognitas, ad genera relatas, cum differentiis specificis, nominibus trivialibus, synonymis selectis, locis natalibus, secundum systema sexuake digestas. Tomus 2. Impensis Laurentii Salvii, Holmiae.

LORBEER G. 1934. Die Zytologie der Lebermoose mit besonderer Berücksichtigung allgemeiner Chromosomenfragen 1. - Jahrbücher für wissenschaftliche Botanik 80: 567-818.

MACiCKA-PAWLIK T. \& WiLCZYŃSKA W. 1996. Zbiorowiska roślinne starorzeczy w dolinie środkowego biegu Odry. - Acta Universitatis Wratislaviensis 1735, Prace Botaniczne 64: 73-120.

MattuschKA H. G. 1779. Enumeratio stirpium in Silesia sponte crescentium in usum herborisantium. Sumptibus Guilielmi Theophili Kornii, Vratislaviae.

MatuszKiewicz W. 2005. Przewodnik do oznaczania zbiorowisk roślinnych Polski. s. 537. Wydawnictwo Naukowe PWN, Warszawa. 
Mirek Z., PięKoś-Mirkowa H., ZająC A. \& ZająC M. 2002. Flowering plants and pteridophytes of Poland. A checklist. - W: Z. MiReK (red.), Biodiversity of Poland. 1, s. 442. W. Szafer Institute of Botany, Polish Academy of Sciences, Kraków.

MÜLLER K. 1941. Beiträge zur Systematik der Lebermoose. II. - Hedwigia 80: 90-118.

MÜLLER T. \& GöRS S. 1960. Pflanzengesellschaften stehender Gewässer in Baden-Württemberg. - Beitrage zur Naturkundliche Forschung in Südwestdeutschland 19(1): 60-100.

OchYRa R. 1985. Roślinność lejków krasowych w okolicach Staszowa na Wyżynie Małopolskiej. - Monographiae Botanicae 66: 1-136.

ORZECHOwSKI R. 2012. Zespół lęgowych ptaków wodnych starorzeczy środkowej Odry. - Ptaki Śląska 19: $7-24$

OT'AHEL'ovÁ H.1995. Lemnetea. W: - M. ValachoviČ (red.), Rastlinné spoločenstwa Slovenska. 1. Pionierska vegetácia. s. 131-150. Veda, Bratislava.

Passarge H. 1996. Pflanzengesellschaften Nordostdeutschlands. 1. Hydro- und Therophytosa. s. 283. J. Cramer, Berlin - Stuttgart.

PodBielkowski Z. 1968. Roślinność stawów rybnych województwa warszawskiego. - Monographiae Botanicae 27: 3-122.

Potт R. 1980. Die Wasser- und Sumpfvegetation eutropher Gewässer in der Westfälischen Bucht - Pflanzensoziologische und hydrochemische Untersuchungen. - Abhandlungen aus dem Landesmuseum für Naturkunde zu Münster in Westfalen 42(2): 1-156.

Pотт R. 1995. Die Pflanzengesellschaften Deutschlands. 2 Aufl. s. 622. E. Ulmer, Stuttgart.

ProćKów J. \& SzCŹ̨́́NIAK E. 2009. Zbiorowiska roślinne rezerwatu „Torfowisko Kunickie” koło Legnicy - ocena dynamiki i zagrożeń. - Acta Botanica Silesiaca 4: 43-90.

Rennwald E. (red.). 2000. Rote Liste der Pflanzengesellschaften Deutschlands mit Anmerkungen zur Gefährdung. - W: E. RENNWALD (red.), Verzeichnis und Rote Liste der Pflanzengesellschaften Deutschlands. - Schriftenreihe für Vegetationskunde 35: 393-592.

Rivola M. 1967. Příspěvky k poznání játrovek rodu Riccia I. Riccia rhenana Lorbeer v jižních Čechách. - Preslia 39: 72-82.

Schratt L. 1993. Lemnetea. - W: G. GrabHerR \& L. Mucina (red.), Die Pflanzengesellschaften Österreichs. Teil II. Natürliche waldfreie Vegetation, s. 53-78. G. Fischer Verlag, Jena - Stuttgart - New York.

Schubert R., Hilbig W. \& Klotz S. 1995. Bestimmungsbuch der Pflanzengesellschaften Mittel- und Nordostdeutschlands. s. 403. G. Fischer, Jena - Stuttgart.

SCHUMACKER R. \& VÁŇA J. 2005. Identification keys to the liverworts and hornworts of Europe and Macaronesia (Distribution and status). Wyd. 2. s. 209. Sorus, Poznań.

SLAVNIĆ Z. 1951. Prodrome des groupements végétaux nitrophiles de la Voivodine (Yougoslavie). - Series for Natural Science, Matica Srpska 1: 84-169.

Sовотка D. 1958. Nowe stanowisko Riccia rhenana Lorbeer w Polsce. - Fragmenta Floristica et Geobotanica 4(1-2): 221-224.

Söderström L., Hagborg A., von Konrat M., Bartholomew-Began S., Bell D., Briscoe L., Brown E., Cargill D. C., Costa D. P., Crandall-Stotler B. J., Cooper E. D., Dauphin G., Engel J. J., Feldberg K., Glenny D., Gradstein S. R., He X., Heinrichs J., Hentschel J., Ilkiu-Borges A. L., Katagiri T., Konstantinova N. A., Larraín J., Long D. G., Nebel M., Pócs T., Felisa Puche F., Reiner-Drehwald E., Renner M. A. M., Sass-Gyarmati A., Schäfer-Verwimp A., Moragues J. G. S., Stotler R. E., Sukkharak P., Thiers B. M., Uribe J., VáŇa J., Villarreal J. C., WigginTON M., Zhang L., ZhU R-L. 2015. World checklist of hornworts and liverworts. - PhytoKeys 59: $1-828$. 
SpaŁeK K. 2005. Rzadkie i ginące zbiorowiska z klas Lemnetea minoris i Potametea na Równinie Opolskiej. - Fragmenta Floristica et Geobotanica Polonica 12(1): 123-133.

Stebel A. 2019. Gatunki z rodzaju Riccia L. sect. Ricciella (A.Braun) Bisch. w województwie śląskim. - W: L. Frey (red.), 58. Zjazd Polskiego Towarzystwa Botanicznego. Botanika bez granic. Streszczenia referatów i plakatów, s. 30-31. Polskie Towarzystwo Botaniczne, Instytut Botaniki im. W. Szafera, Kraków.

Stebel A. \& KraJewski Ł. 2019. Interesujące gatunki mszaków we florze województwa śląskiego. - Fragmenta Floristica et Geobotanica Polonica 26(2): 359-368.

Stebel A. M. \& Stebel A. 1998. Szata roślinna projektowanego użytku ekologicznego „Stary Staw“ w Kotlinie Oświęcimskiej. - Ochrona Przyrody 55: 77-106.

Šumberová K. 2011. Lemnetea. - W: M. ChytrÝ (red.), Vegetation of the Czech Republic. 3. Aquatic and Wetland Vegetation, s. 96-99. Academia, Praha.

SzWEYKOwSKI J. \& KoźLICKA M. 1966. Wątrobowce wyspy Wolina i południowo-wschodniego Uznamu. - Badania Fizjograficzne nad Polską Zachodnią 18: 155-180.

Tomaszewicz H. 1979. Roślinność wodna i szuwarowa Polski (Klasy: Lemnetea, Charetea, Potamogetonetea, Phragmitetea) wg stanu zbadania na rok 1975, s. 325. Rozprawy Uniwersytetu Warszawskiego, Warszawa.

VaILlant S. 1723. Botanicon parisiense. Operis majori prodituri prodromus. Apud Petrum Vander, Lugduni Batavorum.

WILCZYŃSKA W. 1988. Roślinność glinianek położonych na obszarze gminy Malczyce (województwo wrocławskie), ze szczególnym uwzględnieniem mszaków. - Acta Universitats Wratislaviensis 974, Prace Botaniczne 40: 61-90.

\section{SUMMARY}

The paper presents the distribution and habitat conditions of the Riccietum fluitantis association in oxbow lakes of south-western Poland. Eleven localities of this community were found in 2000-2018. The studied patches of Riccietum fluitantis develop in eutrophic and mesotrophic waters of 5-80 cm deep and pH $6.9-8.2$, on silty, sandy or silty-sandy bottom. Its phytocenoses occupy small areas, usually covering $5 \mathrm{~m}^{2}$ to $50 \mathrm{~m}^{2}$, rarely to $1 \mathrm{ha}$. The floristic composition and habitat conditions of the studied patches are similar to those of previously noted stations of this community in Poland and other European countries (Tab. 1). The threats to Riccietum fluitantis in oxbow lakes in south-western Poland include changes in the levels and physicochemical properties of the water, frequent isolation from flooding floodplains, and droughts which are increasing from year to year. Most of the oxbow lakes in which Riccietum fluitantis was found are strongly eutrophic, especially in waterbodies located in fields and meadows.

Identification of Riccietum fluitantis is problematic, due to the significant similarity of Riccia fluitans to other species of sect. Ricciella. Their aquatic forms are practically indistinguishable; correct identification of these species is practically possible only in the presence of terrestrial forms. This is especially true for the closely related Riccia rhenana.

In order to distinguish these species it is necessary to check whether the terrestrial form occurs at the site of the phytosociological relevé, or collect some thalli and grow them in the laboratory on moist soil. If determination is not possible, such information should be included in the work, for example as Riccia fluitans s.l.

Wptynęto: 10.05.2020 r.; przyjęto do druku: 30.09.2020 r. 